\title{
Detection of Pancreatic Cancer in Individuals with New - onset Diabetes Mellitus using Endoscopic Ultra Sound Imaging
}

\author{
B. V. Sathish Kumar, V. P. Chandra Reddy, T. Vineela
}

\begin{abstract}
Pancreatic cancer (PC) is 1 of the deadliest cancers, having a 5-year survival rate of $8 \%$. Without Noteworthy propels in screening and treatment, the pc is relied upon to be the subsequent using reason for disease passing in 2020. Regardless of the truth that 5\% to ten\% of all pc instances related to hereditary or familial problems, the staying ninety\% are sporadic. Human beings with new-starting diabetes mellitus had been awesome as excessive-hazard accumulating is massive that the blessings of screening. The capability to understand diabetes kind 2 diabetes computer-associated and distinguishing proof of biomarkers for this amassing will encourage early location of laptop.
\end{abstract}

Keywords: clinical trials, diabetes mellitus, pancreatic cancer, screening.

\section{INTRODUCTION}

Pancreatic cancer (PC) is probably the deadliest illness wherein harmful (destructive) cells structure in the tissues of the pancreas. It is anticipated to turn into the Second driving purpose behind harm related passings inside the america through 2020 [1]. The pancreas is an organ situated behind the stomach and sooner than the spine. The pancreas produces stomach related juices and hormones that immediate glucose. Cells called exocrine pancreas cells produce the stomach related juices, while cells called endocrine pancreas cells produce the hormones. Limit of pancreatic tumors start inside the exocrine cells. Pancreatic harmful increment is profoundly additional common in men than in ladies, customarily taking region after age 45 . Pancreatic infirmity's affinity to unfurl unobtrusively before quality of mind makes it one of the most antagonistic threatening blast take a gander at. In most through the utilization of far of cases, appearances basically make after pancreatic harmful development has advanced and begun out to spread. Given that more than ninety five $\%$ of pancreatic dangerous increment is the exocrine sort, we will depict the ones part impacts first, trailed through the utilization of feature impacts of abnormal styles of pancreatic sickness. Toward the beginning, pancreatic harmful increment will in mainstream be tranquil and perfect as it creates. Pointers for workstation won't blessing until past due inside the turmoil movement

In addition, depend on the spot of the tumor [2]. Two or three thirds of PC times develop inside the head of the

\footnotetext{
Revised Manuscript Received on 14 September, 2019.

B.V.Sathish Kumar, Assistant Professor, Ece Department, VVIT, Guntur, AndhraPradesh, India.

V.P.Chandra Reddy, Assistant Professor, Ece Department, VVIT, Guntur, AndhraPradesh, India.

T.Vineela,Assistant Professor, Ece Department, VVIT, Guntur, AndhraPradesh, India.
}

pancreas, which sits in the twist of the duodenum. Most patients with tumors in this district appreciate weight decrease (ninety two\%) and jaundice (eighty two\%); distinctive regular appearances may likewise furthermore contain stomach torment (seventy two\%), anorexia (sixty $4 \%$ ), dull pee (sixty three\%), and dust toned stool $(62 \%)$ achieved by means of impediment inside the bile system. Patients with threat in the edge or tail of the pancreas routinely declared unexplained weight reduction and may in like manner give hard to get stomach or mid diminishing back torment, sickness, anorexia, and early satiety.

An unexpected aversion for espresso, wine, or smoking is most likely an early indication for huge individuals with the pollution, appearing to be 7 to 2 years sooner than the start of misery or jaundice [3]. Abrupt hyperglycemia and newbeginning diabetes mellitus (NODM) may likewise in addition in like manner address early appearances. Research has indicated that diabetes mellitus is associated with PC; basically half of everybody with workstation have diabetes on the hour of discovering [4]. Somewhere inside the scope of seventy five $\%$ to $88 \%$ of those people had been chosen to have diabetes in the earlier years [5].

The tumor center point and metastasis structure is done to association various harmful developments. Be that as it could, this association of collection isn't in every case often completed for PC while you remember that various sufferers with pc have impelled disease and despise cautious sorting out [6]. The more noteworthy typical procedure for portrayal is to decide whether the danger is cautiously resectable, periphery resectable, or unresectable. Resectable PC is ordinarily threatening development this is kept to the pancreas and might be actually removed with a Whipple system without a cure prior. Periphery resectable workstation is every now and again delineated as being controlled to the pancreas with limited consideration of close by veins, which include the unmatched mesenteric stockpile way, most crucial mesenteric vein, and section vein [7]. Periphery resectable pc may wind up resectable with neo adjuvant cure. Unresectable workstation is portrayed as being secretly amazingly great pollution that has advanced into or encases the more prominent a part of the edge of goliath veins or ailment this is metastatic Generally eighty\% of PC times are dissected after the contamination has gotten secretly improved, having unfurl to include common lymph center points (Fig.1) [8]. Threatening blast that is compelled to the pancreas is related 
with an imagined 34\% 5-year relative perseverance value; this continuance value drops when defilement has unfurl past the pancreas (Fig.2).

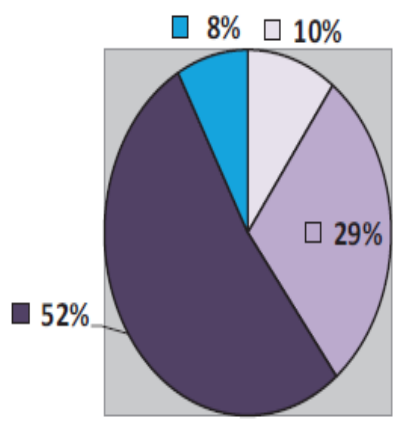

\begin{tabular}{|l|}
\hline$\square$ Disease Localized to Primary \\
Site \\
$\square$ Disease has Sprerad to \\
Regional Lymph Nodes \\
$\square$ Disease has Metastasized to \\
Distant Sites \\
$\square$ Unknown/Unstaged \\
\end{tabular}

Fig. 1. Percent of PC cases by stage.

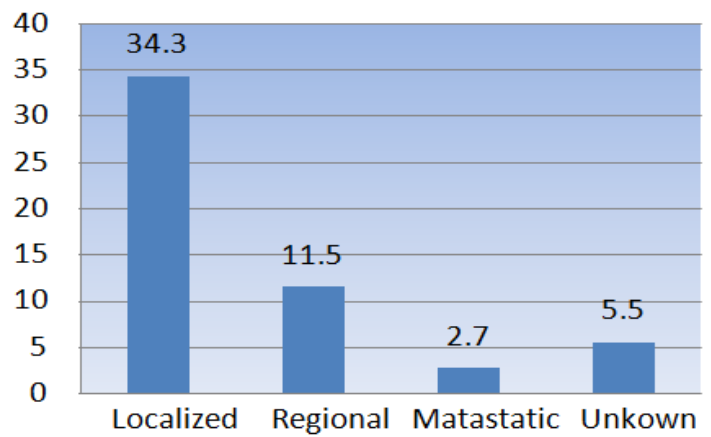

Fig. 2. Five-year relative survival of pancreatic cancer by stage.

A $34.3 \%$ 5-year endurance rate related with sickness limited to the essential site instead of an illness that has spread to provincial lymph hubs $(11.5 \%)$ or metastatic infection $(2.7 \%)$; This proposes early recognition is the way to endurance. The instance of the arranging are known to have 5.5\% 5-year endurance rate.

pc endurance can be improved with the assistance of early identification. pancreatic intraepithelial neoplasia (PanINs) considered a forerunner injury for workstations and range from an expansion in Panin-1 through Panin-three [5]. PC transforms into identified in $7 \%$ of individuals with a particular hereditary change plunge, with the typical cost for basic items costs resection seventy five $\%$ and 5-year of 24\%. forerunner injuries, which incorporate PanINs and intraductal papillary mucinous neoplasms were recognized in around $34 \%$ of the individual tests, with $12 \%$ of people this procedure of careful resection. records have as of late displayed at the Society of Medical Oncology yank yearly session indicated that the adjuvant medication improvement can likewise blasting uncommon endurance after resection, in spite of the reality the long haul yet don't must have [9].

There are numerous components of dangers that could add to the advancement of PCs. Tobacco use has been chosen for the development of the threats of workstation 2overlay [10]. overwhelming liquor consumption, weight issues, pancreatitis industrious, non-O blood bunch $\mathrm{ABO}$, top notch rendition of the hereditary and family records of ailment has additionally been analyzed as the risk [10,11]. At last, diabetes mellitus has been known as a hazard segment. For further discourse on the connection among diabetes and following workstation.

\section{Diabetes and Pancreatic Cancer}

The romance among diabetes and the PC is a confounded one, and when the investigation of diabetes comparative with existing pc. Diabetes is extra basic in patients with pc contrasted and patients with basic malignancies selective [12]. One discovered diabetes saw in forty-seven $\%$ of patients enlisted with pc; some take another look stipulates that $68 \%$ of patients enrolled with the PC has diabetes [12]. Epidemiological considers prescribe that long haul diabetes, or diabetes have a present for at any rate 3 years, is a component of danger, with 1.5-2.0 degrees relative peril [13]. It is anticipated that the hyper insulinemia and the expanded degree of genius incendiary mixes add to this extended chance. Proceeding with this view, 1 portion reaction meta-assessment found that the expense of PCs expanded by $14 \%$ with the assistance of every $10 \mathrm{mg} / \mathrm{dL}$ increment in fasting blood glucose [14]. In any case, there might be a worldly connection among diabetes and workstation (picture three), and the pervasiveness of diabetes can be partitioned into three significant hint: long haul diabetes, or diabetes is available for a long time in any event; Nodm, or diabetes is available under 1 to 3 years; and abrupt harm incessant, stable diabetes [15].
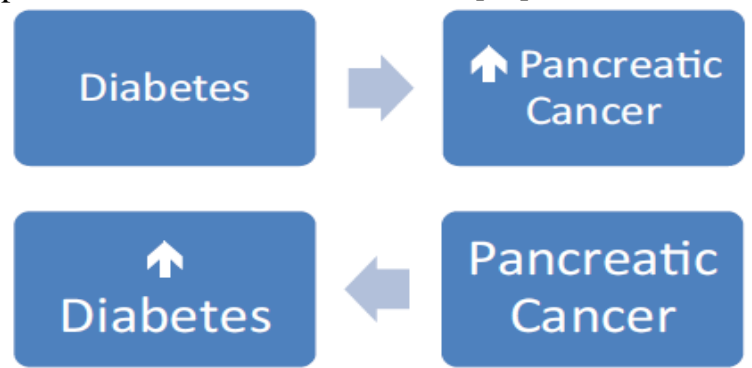

Fig. 3. The relationship of diabetes and PC

Longstanding diabetes (defined as being present for 3 or more years) is a risk factor for the development of diabetes. PC increases the risk of new-onset diabetes (variably defined as less than 1-3 years) as well as Unexpected decay of incessant, sturdy diabetes. There is evidence presenting that NODM conveys a 4-to eight-overlay elevated hazard of pc improvement within the preliminary 3 years of meeting symptomatic standards for diabetes $[5,16]$. One take a look at noticed the predominance of NODM as basically better in sufferers with computer contrasted and manipulate sufferers or patients with normal malignancies [17]. Exceptional resources have decided that seventy $4 \%$ to $88 \%$ of patients with laptop were determined to have diabetes interior two years in advance than the determination of $\mathrm{pc}[4,5,16]$. The american Diabetes association has perceived a pancreatogenic subtype of diabetes related to pancreatic exocrine disorder named kind $3 c$ diabetes [18]. Techniques that motive diffuse and massive harm to the pancreas, as an instance, interminable pancreatitis, are regular accountable events of this subtype; even though, only a little little little bit of the pancreas is covered whilst diabetes creates in sufferers with pc, imparting an trade pathophysiologic thing aside from number one beta-mobile misfortune. 


\section{Early Pancreatic Cancer}

Due to treacherous scientific route and indistinct component effects the pancreatic malignant increase dedication is generally late, with surely 1520percentpatients giving conceivably reparable sickness. It's miles, along those traces, essential to distinguish the sufferers with computer at beginning times of the illness whilst tumors is probably agreeable to careful resection. For unresectable and fringe resectable pc it's far consensual to play out a biopsy to have a cyto/histological affirmation of danger earlier than remedy. Be that as it may, for patients giving in a well timed fashion resectable illness, the process of biopsy is an increasing number of clean to refute. Endoscopic ultrasound (EUS) is a full-size technique supporting the notion and organizing of pc. EUS-guided tissue acquiring is an entrenched equipment to reveal the threatening idea of a pancreatic harm. This survey facilities across the pastime of EUS inside the stop and organizing of computer, and capabilities the competition diagnosed with the interest of EUS-guided tissue procurement in the preoperative appraisal of patients giving right away resectable tumors (early pc).

\section{Early diagnosis of Pancreatic Cancer: a field for EUS?}

The quiet idea of computer offers to its terrible result. Yachida et al. Assessed that maximum of sufferers with laptop are just analyzed within the ultimate 2 of the 10 -years tumorigenic technique [19]. Regrettably, early recognition of computer is generally tough, due to the fact there are positive policies for fine dedication. A crucial exertion in seeking out screening strategies of pc is on-going in the route of the maximum latest years. This technique has been regarded as a choice to recognize beginning times and preunstable conditions. This technique has been prescribed to human beings with over five\% of life-time danger for the infection. Be that as it is able to, it's far wonderful that the frequency of computer is especially low (lifetime threat $1.3 \%$ ), so large screening can not be considered as potential [20]. Experts prescribe to display screen people with extra than 10-overlay extended danger, as the instance of familial pc and some hereditary problems associated with an elevated danger [21-24]. Later meta-exam has tested the capability process of attractive reverberation imaging (MRI) and EUS in the reconnaissance of excessive-threat sufferers for $\mathrm{pc}$, for spotting pancreatic sores, with comparative exactness for the two strategies [25, 26]. Radiological considers are primary in evaluation and organizing of laptop. Anyways, they have exceptional constraints, together with the fluctuation of the elucidating phrasing to symbolize illness degree and insufficient documentation of disease locales, that might have an effect at the medical fundamental management approach [27]. Multi indicator registered tomography (MDCT), carried out with a pancreatic conference is usually taken into consideration as the method for choice for starting assessment inpatients with the doubt of pc [27,28]. X-ray has comparative affectability and particularity; notwithstanding, because of absence of massive accessibility, required talent, greater charge, and restrained spatial goals while contrasted with CT, it isn't always notably utilized as the critical imaging technique $[27,29,30]$. The principle venture of MRI is to assess is constricted pancreatic injuries and to greater resultseasily describe uncertain liver sores recognized at earlier CT. Furthermore, it permits a first rate mind-set at the biliary and pancreatic pipe, showing the "twofold pipe sign", profoundly specific for pc [27,29,30,31].

The essential imaging approach for the assessment of pancreatic infections, such as strong pancreatic sores, is EUS, with centered sensitivities somewhere in the form of 87 and 100\% [32-34]. EUS has showed an altogether higher exactness for the analysis of computer while com-pared to CT. EUS is mainly valuable for id of tumors $<30 \mathrm{~mm}$. In this setting, it exhibits an affectability of $93 \%$ contrasted with $53 \%$ for MDCT and $67 \%$ for MRI [33,35,36]. Notwithstanding this high exactness, EUS has a few impediments in the differential analysis among PC and some non-neoplastic sores, for example, mass framing interminable pancreatitis or immune system pancreatitis [32]. There are a few techniques to improve this precision and over-come its restrictions. Propelled imaging identified with EUS has appeared to improve the portrayal of strong pancreatic injuries, among them differentiate upgraded EUS (C-EUS) and EUS-guided elastography. C-EUS depends on the organization of a particular contrastagent, which features the microvasculature of pancreatic masses during constant assessment. PC as a rule displays a hypovascular design, neuroendocrine tumors a hypervascular example and massshaping ceaseless pancreatitis an isovascular one [37]. Yamashitaet al. Detailed that hypo upgrade conduct determined pancreatic carcinoma to have an affectability of $95 \%$ and particularity of $89 \%$, discoveries bolstered by different creators [32,38,39]. EUS-guided elastography, a strategy that assesses tissues solidness by estimating the level of strain created by outer weight, has exhibited to be a superb instrument for the board of pancreatic sores [40]. Both a subjective assessment (in view of the shading guide and pat-tern) and a quantitative assessment (in view of strain proportion or strain histogram) are accessible these days. By and large, hard sores, indicated bya blue example, high strain proportion $(>10)$ or low pressure histogram $(<50)$, are usually recognized with threat [41]. No matter the fact that affectability of EUS-guided elastography for determine risk is immoderate it stilllacks particularity $[42,43]$. Apart from match for improving sore portrayal, each C-EUS and elastography, moreover assist in the determination of the nice sector to perform EUS-guided tissue securing each time showed. Another technique to enhance analytic exactness is using speedy nearby evaluation (ROSE) of the example by using an achieved pathologist at some point of the EUS take a look at. Fact be told, ROSE emerge as placed to result in less rehashed techniques and better level of entire willpower as it decides if the suction got is ideal enough or notto license a conclusive analysis [44].

\section{EUS in Pancreatic Cancer staging \& RESULTS}

The desire with reference to resectability repute need to be made via settlement at multidisciplinary dialogs, in immoderate volume focuses $[30,45]$. Despite the fact that, laptop arranging have become inside the past depending at 
the TNM association, it's miles currently characterized with an an increasing number of unique characterization. Pc must now be portrayed as resectable, fringe resectable, privately advanced, unresectable or metastatic. Every the type of highlights willguide treatment dedication and consist of significant prognostic factorsfor staying power [30,27,46]. Both national comprehensive most cancers network (NCCN) and european Society for medical Oncology (ESMO) guidelines recollect MDCT angiography as a substantial method $[30,45]$. Positron emanation tomography could no longer include masses of records for organizing laptop and is not as of now cautioned. ESMO paintings-up recommends appearing EUS for in addition appraisal if beginning MDCT does not find distantmetastasis, while NCCN pointers recommend that EUS is complimentary to CT in selected instances [30,45,47]. Reality be instructed, it is generallyaccepted that EUS has a large system in preoperative arranging. Aside from its functionality to outline tumor region and duration, it famous a first rate exactness for recognizing lymph hub metastasis, vascular intrusion and foreseeing resectability. In an ongoing metaresearch of 29studies (counting 1330 patients), EUS indicated a pooled sensitivityof sixty nine $\%$ and particularity of $81 \%$ for metastatic lymph hub detection,and a pooled affectability of eighty five $\%$ and explicitness of ninety one $\%$ for vascularinvasion. This exam contrasted EUS and CT with find out arterialand venous attack and presumed that each perform similarlyfor venous intrusion but CT might be most important in comparing arterialinvasion, to be unique the celiac hub and standard mesenteric supply direction. There had been no contrasts amongst EUS and CT in anticipate ing resectability, with the preceding indicating a pooled affectability of $90 \%$ and particularity of $86 \%$. Additionally, the plausibility of regular with-shaping tissue procurement at some stage in EUS changed into likewise featured in this meta-examination, mainly its task inside the portrayal of a everyday portocaval lymph hubs, ascitic liquid, peritoneal knobs as well as presumed liver metastasis. As a consequence, EUS also can now be taken into consideration as substantial of care along MDCT in preoperative organizing of pancreatic carcinoma [48].

\section{CONCLUSION}

The potential to recognize kind 2 diabetes from computerassociated diabetes and the identification of a biomarker for this collecting may want to encourage earlier discovery of pc. On the way to do as such, Endoscopic ultrasound (EUS) can in all likelihood be applied for the analysis and organizing of pc, as it has better affectability and particularity contrasted and exceptional handy structures. Likewise, EUS-guided tissue procurement is a settled device to exhibit the threatening concept of a pancreatic damage.

\section{REFERENCES}

1. Rahib L, Smith BD, Aizenberg R, Rosenzweig AB, Fleshman JM, Matrisian LM.Projecting malignancy occurrence and passings to 2030. The sudden weight of thyroid, liver, and pancreas malignant growths inside the united states of america. Malignant boom Res.2014;seventy four(11):2913-2921.

2. De 1. A. Cruz MS, young AP, Ruffin MT. Conclusion and the executives of pancreatic malignant boom. Am Fam health practitioner. 2014;89(eight):626-632.

3. Gullo L, Tomassetti P, Migliori M, Casadei R, Marrano D. Do early side results of pancreatic ailment exist which can permit a previous finding? Pancreas. 2001;22(2):210-213.

4. Pannala R, Leirness JB, Bamlet WR, Basu A, Petersen GM, Chari ST. Pervasiveness and scientific profile of pancreatic malignant boom associated diabetes mellitus. Gastroenterology. 2008;134:981-987.

5. Chari ST, Kelly okay, Hollingsworth MA, et al. Early identity of sporadic pancreatic malignant growth: summative survey. Pancreas. 2015; forty 4(5):693.

6. American Society of clinical Oncology (ASCO) e most cancers.Net. Pancreatic malignancy - degrees. Https://www.Most cancers.Internet/malignant boom sorts/pancreatic-sickness/tiers. Gotten to July 13, 2018.

7. Shaib WL, Ip A, Cardona ok, et al. Modern-day the executives of fringe resectable and privately improved unresectable pancreatic malignant increase. Oncologist.2016;21(2):178-187.

8. Country wide most cancers Institute. Diviner malignant growth element certainties: pancreas disorder. Https://seer.Most cancers.Gov/statfacts/html/pancreas.Html. Gotten to July thirteen, 2018.

9. Conroy T, Hammel P, Hebbar M, et al. Unicancer GI PRODIGE 24/CCTG PA. 6 preliminary: a multicenter normal randomized degree III preliminary of adjuvant mFOLFIRINOX in place of gemcitabine (jewel) in patients with resected pancreatic ductal adenocarcinomas Http://ascopubs.Org/doi/abs/10.1200/JCO.2018.36

.18_suppl.LBA4001. Gotten to July 10, 2018.

10. Overbeek KA, Cahen DL, Canto MI, Bruno MJ. Observation for neoplasia inside the pancreas. Pleasant Pract Res Clin Gastoenterol. 2016;30(6):971-986.

11. Beeghly-Fadiel A, Giri A, Bastarache L, Pulley J, Warner J, Denny J. ABO blood category and malignant growth threat: essential discoveries from a marvels assessment.[abstract]. In: lawsuits of the yank affiliation for cancer research Annual meeting 2017; April 1-5, 2017; Washington, DC. Conceptual 1293. Doi: Https://doi.Org/10.1158/1538-7445.AM2017-1293.

12. Aggarwal G, Kamada P, Chari ST. Pervasiveness of diabetes mellitus in pancreatic disorder contrasted with ordinary malignant growths. Pancreas. 2013;40 (2):198.

13. Andersen DK, Korc M, Petersen GM, et al. Diabetes, pancreatogenic diabetes, and pancreatic malignancy. Diabetes. 2017;66(5):11031110 .

14. Liao WC, Tu YK, Wu MS, Lin JT, Wang HP, Chien KL. Blood glucose interest and risk of pancreatic illness: methodical audit and doseresponse meta-studies. BMJ. 2015;349:g7371.

15. Forthright R. Pancreatic ailment initiated diabetes: a deliver of suggestion. Oncol times. 2017;39(19):1;8.

16. Sah RP, Nagpal SJ, Mukhopadhyay D, Chari ST. New bits of knowledge into pancreatic malignant growth incited paraneoplastic diabetes. Nat Rev Gastronterol Hepatol. 2013;10(7):423-433. Https://doi.Org/10.1038/nrgastro.2013.Forty nine.

17. Vasen H, Ibrahim I, Ponce CG, et al. Benefit of reconnaissance for pancreatic malignant boom in immoderate-chance human beings: end end result of long haul planned observe-up ponders from three ecu grasp focuses. J Clin Oncol. 2016;34(17):2010-2019. Https://doi.Org/10.1200/JCO.2015.Sixty four.0730.

18. American Diabetes association. End and grouping of diabetes mellitus. Diabetes Care. 2014;37(Suppl1):S81-S90. Https://doi.Org/10.2337/dc14-S081.

19. Overbeek KA, Cahen DL, Canto MI, Bruno MJ. Remark for neoplasia inside the pancreas. Satisfactory Pract Res Clin Gastoenterol. 2016;30(6):971-986.

20. Canto MI, Harinck F, Hruban RH, Offerhaus GJ, Poley J-W, Kamel I, et al. Among country wide cancer of the Pancreas Screening (CAPS) Consortium summit on themanagement of sufferers with progressed risk for familial pancreatic malignant increase. Gut2013; sixty (March (three)):339-forty seven.

21. Greer JB, brand RE. Screening for pancreatic malignancy: modernday evidence and futuredirections. Gastroenterol Hepatol (N Y) 2007; three(December (12)):929-38.

22. Moutinho-Ribeiro P, Coelho R, Giovannini M, Macedo G. Pancreatic cancerscreening: although a hallucination? Pancreatology 2017;17 (October (five)):754-sixty five. 
23. Poruk KE, Firpo MA, Adler DG, Mulvihill SJ. Screening for pancreatic most cancers:why, how, and who? Ann Surg 2013;257(January (1)):17-26.

24. Poruk KE, Firpo MA, Mulvihill SJ. Screening for pancreatic malignant growth. Adv Surg2014;48:one hundred fifteen-36.

25. Corral JE, Mareth KF, Riegert-Johnson DL, Das A, Wallace MB. Symptomatic yieldfrom screening asymptomatic humans at excessive chance for pancreatic malignant boom: ameta-exam of partner ponders. Clin Gastroenterol Hepatol 2018;(may additionally).

26. Signoretti M, Bruno MJ, Zerboni G, Poley J-W, Delle Fave G, Capurso G. Resultsof announcement in people at high-hazard of pancreatic malignant growth: a systematicreview and meta-research. Joined Eur Gastroenterol J 2018;6 (may additionally (four)):489_ ninety nine.

27. Al-Hawary MM, Francis IR, Chari ST, Fishman EK, Hough DM, Lu DS, et al.Pancreatic ductal adenocarcinoma radiology pronouncing format: consensusstatement of the Society of abdominal Radiology and the yankee PancreaticAssociation. Radiology 2014;270 (January (1)):248-60.

28. Zamboni GA, Kruskal JB, Vollmer CM, Baptista J, Callery MP, Raptopoulos VD.Pancreatic adenocarcinoma: estimation of multidetector CT angiography in preop-erative evaluation. Radiology 2007;245 (December (three)):770-8.

29. Ansari NA, Ramalho M, Semelka RC, Buonocore V, Gigli S, Maccioni F. Roleof attractive reverberation imaging in the discovery and portrayal of solidpancreatic knobs: an update. World J Radiol 2015;7 (November (eleven)):361-74.

30. Ducreux M, Cuhna AS, Caramella C, Hollebecque A, Burtin P, crosséré D, et al. Can-cer of the pancreas: ESMO scientific exercise hints for conclusion, treatmentand improvement. Ann Oncol 2015;(September (26 Suppl. Five)):v56-sixty eight.

31. Al-Hawary M. Activity of imaging in diagnosing and arranging pancreatic malignant increase. JNatl Compr Canc Netw 2016;14(can also (5 Suppl.)):678-eighty.

32. Yamashita Y, Kato J, Ueda ok, Nakamura Y, Kawaji Y, Abe H, et al. Differentiation upgraded endoscopic ultrasonography for pancreatic tumors. Biomed Res Int2015;2015:491782.

33. Luz LP, Al-Haddad MA, Sey MSL, DeWitt JM. Uses of endoscopic ultra-sound in pancreatic malignant boom. International J Gastroenterol 2014;20(June (24)):7808-18.

34. Dewitt J, Devereaux BM, Lehman GA, Sherman S, Imperiale TF. Correlation ofendoscopic ultrasound and processed tomography for the preoperative eval-uation of pancreatic ailment: a deliberate audit. Clin Gastroenterol Hepatol2006;four(June (6)):717-25, take a look at 664.

35. Müller MF, Meyenberger C, Bertschinger P, Schaer R, Marincek B Pancre-atic tumors: evaluation with endoscopic US, CT, and MR imaging. Radiology1994; one hundred 90(March (3)):745-fifty one.

36. Wang W, Shpaner A, Krishna SG, Ross WA, Bhutani MS, Tamm EP et al. Use ofEUS-FNA in diagnosing pancreatic neoplasm with out a conclusive mass on CT.Gastrointest Endosc 2013;seventy eight (July (1)):seventy 3-80.

37. Kitano M, Yamashita Y. New imaging methods for endoscopic ultrasonogra-phy: differentiate upgraded endoscopic ultrasonography. Gastrointest Endosc ClinN Am 2017;27 (October (four)):569-83.

38. Dietrich CF, Sahai AV, D'Onofrio M, Will U, Arcidiacono PG Petrone MC, et al.Differential finding of little robust pancreatic sores. Gastrointest Endosc2016;80 four (December (6)):933-forty.

39. Fusaroli P, Napoleon B, Gincul R, Lefort C, Palazzo L, Palazzo M, et al. The clinicalimpact of ultrasound differentiate operators in EUS: a selected survey agreeing tothe levels of proof. Gastrointest Endosc 2016;80 four (October (4)), 587-596.E10.

40. Iglesias-García J, Larĩno-Noia J, Domínguez-Mũnoz JE. New imaging tech-niques: endoscopic ultrasound-guided elastography. Gastrointest Endosc ClinN Am 2017;27(October (four)):551-sixty seven.

41. Iglesias-Garcia J, Lindkvist B, Lari no-Noia J, Abdulkader-Nallib I, Dominguez-Mu noz JE. Differential conclusion of strong pancreatic masses: differentiate upgraded consonant (CEH-EUS), quantitativeelastography (QE-EUS), or both? Joined Eur Gastroenterol J 2017; five(March (2)):236-46.

42. Ignee A, Jenssen C, Arcidiacono PG, Hocke M, Möller k, Saftoiu An, et al. Endo-scopic ultrasound elastography of little sturdy pancreatic sores: a multicenter look at. Endoscopy 2018;(April), http://dx.Doi.Org/10.1055/a-0588-4941 [Epubahead of print].

43. Iglesias-Garcia J, Larino-Noia J, Abdulkader I, Forteza J, Dominguez-Munoz JE.Quantitative endoscopic ultrasound elastography: an actual approach for thedifferentiation of sturdy pancreatic masses. Gastroenterology 2010;139(October(4)):1172-80.
44. Collins BT, Murad FM, Wang JF, Bernadt CT. Rapid close by evaluation for endoscopic ultrasound-guided best-needle biopsy of the pancreasdecreases the occurrence of rehash biopsy techniques. Malignancy Cytopathol2013;121(9):518-24

45. Tempero MA, Malafa MP, Al-Hawary M, Asbun H, Bain A Behrman SW, et al.Pancreatic adenocarcinoma, shape 2.2017, NCCN scientific exercise guidelinesin oncology. J Natl Compr Canc Netw 2017;15(August (8)):1028-sixty one.

46. facet SB, Compton CC. The yankee Joint Committee on cancer: the seventh editionof the AJCC disease organizing manual and the eventual future of TNM. Ann Surg Oncol2010;17(June (6)):1471-4

47. Callery MP, Chang KJ, Fishman EK, Talamonti MS, William Traverso L, LinehanDC. Pretreatment appraisal of resectable and fringe resectable dish creatic malignancy: grasp agreement rationalization. Ann Surg Oncol 2009; sixteen(July(7)):1727-33. 